\title{
Ancient Wood of the Acqualadrone Rostrum: Materials History through Gas Chromatography/Mass Spectrometry and Sulfur X-ray Absorption Spectroscopy
}

\author{
Patrick Frank, ${ }^{*}, \dagger$ Francesco Caruso, ${ }^{\S, \|, \perp}$ and Eugenio Caponetti ${ }^{\S}$ \\ ${ }^{\dagger}$ Department of Chemistry, Stanford University, Stanford, California 94305, United States \\ ${ }^{\ddagger}$ Stanford Synchrotron Radiation Lightsource, SLAC National Accelerator Laboratory, Stanford University, California 94025, United \\ States \\ ${ }^{\S}$ Dipartimento di Chimica Fisica, Università degli Studi di Palermo, 90128 Palermo, Italy \\ "Koninklijk Instituut voor het Kunstpatrimonium-Institut Royal du Patrimoine Artistique (KIK-IRPA), 1000 Brussels, Belgium
}

\section{Supporting Information}

ABSTRACT: In 2008 the rostrum from an ancient warship was recovered from the Mediterranean near Acqualadrone, Sicily. To establish its provenance and condition, samples of black and brown rostrum wood were examined using sulfur Kedge X-ray absorption spectroscopy (XAS) and gas chromatography/mass spectrometry (GC/MS). GC/MS of pyrolytic volatiles yielded only guaiacyl derivatives, indicating construction from pinewood. A derivatized extract of black wood yielded forms of abietic acid and sandaracopimaric acid consistent with pine pitch waterproofing. Numerical fits to the sulfur K-edge XAS spectra showed that about $65 \%$ of the endogenous sulfur consisted of thiols and disulfides. Elemental sulfur was about $2 \%$ and $7 \%$ in black and brown wood,
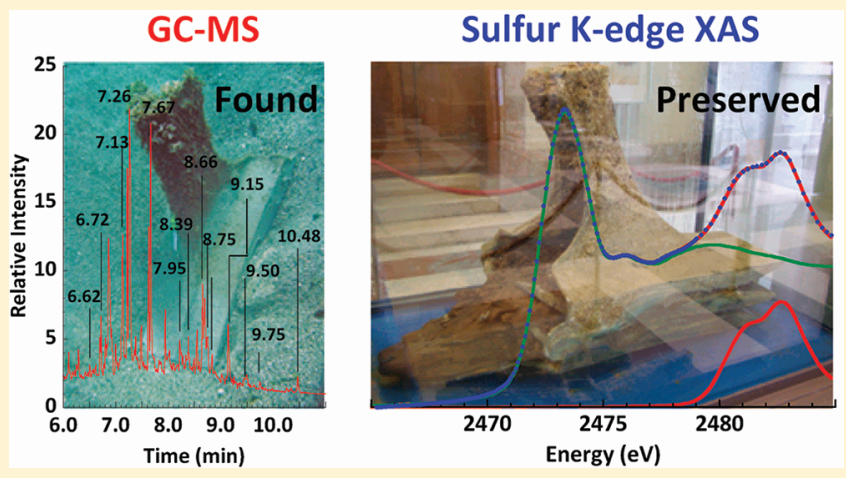
respectively, while pyritic sulfur was about $12 \%$ and $6 \%$. About $2 \%$ of the sulfur in both wood types was modeled as trimethylsulfonium, possibly reflecting biogenic (dimethylsulfonio)propionate. High-valent sulfur was exclusively represented by sulfate esters, consistent with bacterial sulfotransferase activity. Traces of chloride were detected, but no free sulfate ion. In summary, the rostrum was manufactured of pine wood and subsequently waterproofed with pine pitch. The subsequent 2300 years included battle, foundering, and marine burial followed by anoxia, bacterial colonization, sulfate reduction, and mobilization of transition metals, which produced pyrite and copious appended sulfur functionality.

$\mathrm{I}^{\mathrm{n}}$

n September 2008 the bronze naval rostrum from an ancient warship was recovered at about $6 \mathrm{~m}$ depth in the Mediterranean near Messina, Sicily, $200 \mathrm{~m}$ offshore from Acqualadrone. $^{1-4}$ The exposed bronze cowl of the ram was growth-encrusted, but the buried driving center and bottom plate were clean and included the remains of the wooden support. The rostrum wood yielded a ${ }^{14} \mathrm{C}$ date of $277 \pm 83$ B.C.E., ${ }^{2}$ consistent with the earliest naval engagements of the First Punic War. The ship may have been damaged during the Battle of Tyndaris (257 B.C.E.) or of Mylae (260 B.C.E.) just north of Sicily and may have sunk while trying to reach the Roman base at Massana (modern Messina). ${ }^{5}$ Following recovery and prior to restoration, the ram was preserved by submergence in streaming deionized water inside a Plexiglas box.

A general physicochemical characterization of rostrum wood reported a $3 \%(\mathrm{w} / \mathrm{w})$ inorganic fraction that included $19.3 \%$ iron, $13.0 \%$ copper, and $5.6 \%$ lead. $^{3}$ Lead isotopic inductively coupled plasma mass spectrometry (ICPMS) analysis indicated an origin from mines in Cypus or Spain. X-ray diffraction revealed pyrite and $\mathrm{K}_{2} \mathrm{MgCa}\left(\mathrm{SO}_{4}\right)_{3}$, while energy-dispersive $\mathrm{X}$ ray spectroscopy detected iron and sulfur, among other elements.

The original source and treatment of the rostrum wood are unknown. Previous studies have shown that in situ survival of maritime archeological wood requires an anoxic sulfurous environment. ${ }^{6-8}$ Ever since the pioneering study of emergent acidity in the timbers of the 17th century Dutch ship Batavia, ${ }^{9}$ the aerobic conversion of archeological marine wood sulfur into sulfuric acid has become a focus of concern. ${ }^{6-8,10,11}$

To address the questions of the origin and subsequent burial history of the Acqualadrone rostrum, two small wood samples were obtained for analysis: one dark brown and the other black. Gas chromatography-mass spectrometry (GC/MS) was applied both without and with Curie-point pyrolysis to characterize the origin and treatment of the rostrum wood.

Received: January 12, 2012

Accepted: April 15, 2012

Published: April 30, 2012 
Endogenous sulfur was assayed using K-edge X-ray absorption spectroscopy (XAS), followed by numerical fits to speciate the rostrum wood sulfur in terms of the known functional groups of sulfur model compounds. The results are applied to a partial reconstruction of the materials history of the rostrum over a distance of 2300 years.

\section{MATERIALS AND METHODS}

Sulfur K-Edge XAS Analysis. A large section of wood had become detached from the rostrum during the first recovery operations. Two small samples of wood were obtained for XAS examination from the inner part of this archeological section: one was black in color and the other dark brown. These XAS samples were sealed under dinitrogen and shipped from Palermo, Italy, to Stanford University, Stanford, CA, where they were stored under dinitrogen in a Vacuum Atmospheres inert atmosphere glovebox $\left(\leq 1 \mathrm{ppm} \mathrm{O}_{2}\right)$. Black wood consisted of three soft wet cuboids, each about $0.25 \mathrm{~cm}$ on a side, while brown wood consisted of one soft wet piece, $\sim 1 \times 1.5 \times 0.25$ $\mathrm{cm}^{3}$.

For sulfur K-edge XAS spectra, each sample was triturated to a damp fibrous mass using an agate mortar and pestle and then spread across a strip of sulfur-free Kapton tape across a $2 \times 4$ $\mathrm{cm}^{2}$ window in an aluminum frame. The sample was covered with a $6 \mu \mathrm{m}$ thick polypropylene film and kept under a positive helium flow during XAS measurement.

Unless otherwise noted, sulfur K-edge XAS spectra were measured at the Stanford Synchrotron Radiation Lightsource (SSRL) on unfocused 20-pole wiggler beamline 4-3 under dedicated operating conditions of $150-180 \mathrm{~mA}$ ring current, with a $2.0 \mathrm{~T}$ wiggler field, a liquid nitrogen cooled $\mathrm{Si}[111]$ monochromator, and a rhodium-coated $M_{0}$ mirror. Beamline $\Delta E / E=10^{-4}$, and the XAS resolution is $0.65 \mathrm{eV}$, as the convolution of the sulfur corehole lifetime width of $0.6 \mathrm{eV},{ }^{12}$ with the beamline 4-3 monochromator resolution at the sulfur K-edge of $0.25 \mathrm{eV}$. The $I_{0} \mathrm{X}$-ray intensity was measured using an in-line nitrogen-filled ionization detector. All XAS spectra were detected as fluorescence excitation at the sulfur $\mathrm{K} \alpha$ emission line using a passivated implanted planar silicon (PIPS) detector. Individual K-edge scans were calibrated against the first pre-edge feature of solid sodium thiosulfate hexahydrate, which was assigned to $2472.02 \mathrm{eV}$. Sodium thiosulfate calibration scans bracketed the model compound measurements and the grouped rostrum wood XAS scans. A total of six scans were obtained for each rostrum wood sample.

Model compounds for XAS analysis were purchased from Aldrich Chemicals and used as received. S-(tert-butylthio)-Lcysteine ( $\mathrm{pH} 7.1$ ), methionine sulfoxide ( $\mathrm{pH} 7.1)$, methionine sulfone ( $\mathrm{pH} 7.2)$, sodium methyl sulfate $(\mathrm{pH} 7.2)$, and 5,5'dithiobis(2-nitrobenzoate) ( $\mathrm{pH} 7.2)$ were measured as solutions in aqueous $0.25 \mathrm{M}$ sodium citrate buffer. Di-tertbutyl disulfide $(46.3 \mathrm{mM})$, diphenyl disulfide $(50 \mathrm{mM})$, and 2,1,3-benzothiadiazole $(90.6 \mathrm{mM})$ were measured in $p$-xylene solution. 1,3-Propylene cyclic sulfate and dimethyl L-tartrate 2,3-O-sulfate were measured in $\mathrm{N}, \mathrm{N}$-dimethylformamide solution, and 1,2:5,6-di-O-isopropylidene-D-mannitol-2,3-O-sulfate was measured as a powder finely ground with boron nitride.

Elemental sulfur ( $51.9 \mathrm{mM}$ as atomic sulfur, filtered solution) in $p$-xylene solution and L-cysteine $(100 \mathrm{mM}$ in $250 \mathrm{mM}$ sodium citrate, $\mathrm{pH}$ 7.1) were measured on SSRL 54-pole wiggler beamline 6-2 equipped with a $\mathrm{Si}[111]$ monochromator and an argon-filled Stern-Heald-Lytle detector and operating in undulator mode at $80-100 \mathrm{~mA}$ ring current. The XAS spectrum of L-cystine was reported previously. ${ }^{13}$ The sulfur Kedge XAS spectrum of L-cysteinesulfinate, in $\mathrm{pH} 8.5$ solution, was kindly provided by Prof. Graham George, University of Saskatchewan, and those of mineralogical pyrite and of pyrrhotite were kindly provided by Dr. Ritimukta Sarangi of SSRL.

Raw XAS data were baseline-adjusted and normalized within the program EXAFSPAK as described previously. ${ }^{14,15}$ EXAFSPAK was written by Prof. Graham George, University of Saskatchewan. Intercomparison of the six successive rostrum black wood scans revealed evidence of slight but progressive photoreduction of the high-valent sulfur. Therefore, only the first scans were used for analysis. The XAS signal-to-noise ratio $(\mathrm{S} / \mathrm{N})$ was evaluated as described in section 1 of the Supporting Information, yielding $1.6 \times 10^{3}$ for black wood and $2.0 \times 10^{3}$ for brown wood.

Following collection of sulfur K-edge XAS spectra, the same rostrum wood samples were digested to homogeneity in $40 \%$ nitric acid and $4 \%(\mathrm{w} / \mathrm{v})$ hydrogen peroxide under microwave heating at Galbraith Laboratories and analyzed for total concentration (ppm) of sulfur, iron, copper, and zinc using inductively coupled plasma atomic emission spectroscopy (ICP-AES).

Rostrum sulfur K-edge XAS spectra were fit using the program DATFIT, which is part of the EXAFSPAK program suite and which employs linear combinations of the sulfur Kedge XAS spectra of functional group model compounds. The goodness-of-fit was calculated as $F=\left(\sum_{n}\left(\chi_{\text {exptl }}-\chi_{\text {fit }}\right)^{2} / n\right)^{1 / 2}$, where $\chi_{\text {exptl }}$ is a data point, $\chi_{\text {fit }}$ is a fitted point, and $n$ is the total number of data points. For numerical fits, all the sulfur K-edge XAS spectra were reprocessed to ensure a uniformly normalized edge jump using the Kaleidagraph application (Synergy Software). ${ }^{16}$ See section 2 in the Supporting Information for procedural details.

The complexity of the rostrum sulfur K-edge XAS spectra required piecewise fits. Thus, the low-valent sulfur XAS region was fit first over the energy range $2460-2480 \mathrm{eV}$. The lowenergy tail of the XAS spectrum of high-valent sulfur was modeled using a pseudo-Voigt line (HWHM (half-width at half-maximum) $=72 \mathrm{eV}$ ) initially set at $2481 \mathrm{eV}$ and allowed to float in energy position and intensity. The final fitted fractions of the component spectra, apart from the pseudo-Voigt line, were rescaled to unit sum and used to construct a single composite sulfur K-edge XAS spectrum representing the lowvalent sulfur in rostrum wood. This composite XAS spectrum was then normalized to unit intensity and used in fits over the full rostrum wood sulfur K-edge X-ray absorption near-edge spectroscopy (XANES) region (2460-2485 eV).

GC/MS Analyses. a Thermo Finnigan GC Ultra coupled with a Thermo Finnigan Polaris Q ion trap mass spectrometer (Thermo Fisher Scientific Inc., Waltham, MA) was used. The Thermo-Finnigan injector and interface temperatures were 230 and $290{ }^{\circ} \mathrm{C}$, respectively. GC separation was achieved on a Supelco SLB-5ms fused silica capillary column $(20 \mathrm{~m} \times 0.18$ $\mathrm{mm}$ i.d., $0.18 \mu \mathrm{m}$ film thickness, Supelco, Sigma-Aldrich).

$\mathrm{Cp}-\mathrm{Py}-\mathrm{GC} / \mathrm{MS}$ was carried out by interfacing the pyrolyzer (a Pyromat unit by GSG) to the above-mentioned GC/MS instrument. The temperature of the pyrolyzer interface was 250 ${ }^{\circ} \mathrm{C}$, and the pyrolysis was carried out for $10 \mathrm{~s}$. The standby temperature of the pyrolyzer was $150{ }^{\circ} \mathrm{C}$, and the clean and the equilibration times were $10 \mathrm{~s}$. The temperatures of the injector and of the GC/MS interface were 250 and $290{ }^{\circ} \mathrm{C}$, respectively. 
Separation was achieved employing the same column as used for GC/MS analysis. See section 3.2 in the Supporting Information for the full procedural details.

\section{RESULTS}

X-ray Absorption. The black wood and brown wood XAS samples were analyzed for total sulfur, iron, copper, and zinc (Table 1).

Table 1. Elemental Analysis $\left(\mathrm{ppm}^{a}\right)$ of the Acqualadrone Wood XAS Samples

$\begin{array}{lcc}\text { element } & \text { black wood }^{b} & \text { brown wood }^{c} \\ \text { sulfur } & 4.32 \times 10^{4} & 2.68 \times 10^{4} \\ \text { iron } & 3.93 \times 10^{3} & 6.33 \times 10^{2} \\ \text { copper } & 4.20 \times 10^{3} & 7.27 \times 10^{2} \\ \text { zinc } & 1.52 \times 10^{2} & 1.10 \times 10^{2}\end{array}$

${ }^{a}$ Parts per million by weight. The analytical error is $\pm 0.1 \% .{ }^{b} \mathrm{XAS}$ sample 1. ' XAS sample 2.

The remarkable quantities of sulfur in the rostrum samples produced excellent single-scan K-edge XAS spectra (Figure 1), which reveal both low- and high-valent sulfur. The high-valent sulfur is clearly similar to sulfate, ${ }^{17-19}$ which produces XAS features approximately $4 \times$ more intense than those of elemental sulfur or thiol. Most of the rostrum sulfur is thus low-valent, constituting evidence for anoxic burial and extensive colonization by sulfate-reducing bacteria. ${ }^{7,9}$ The variations in

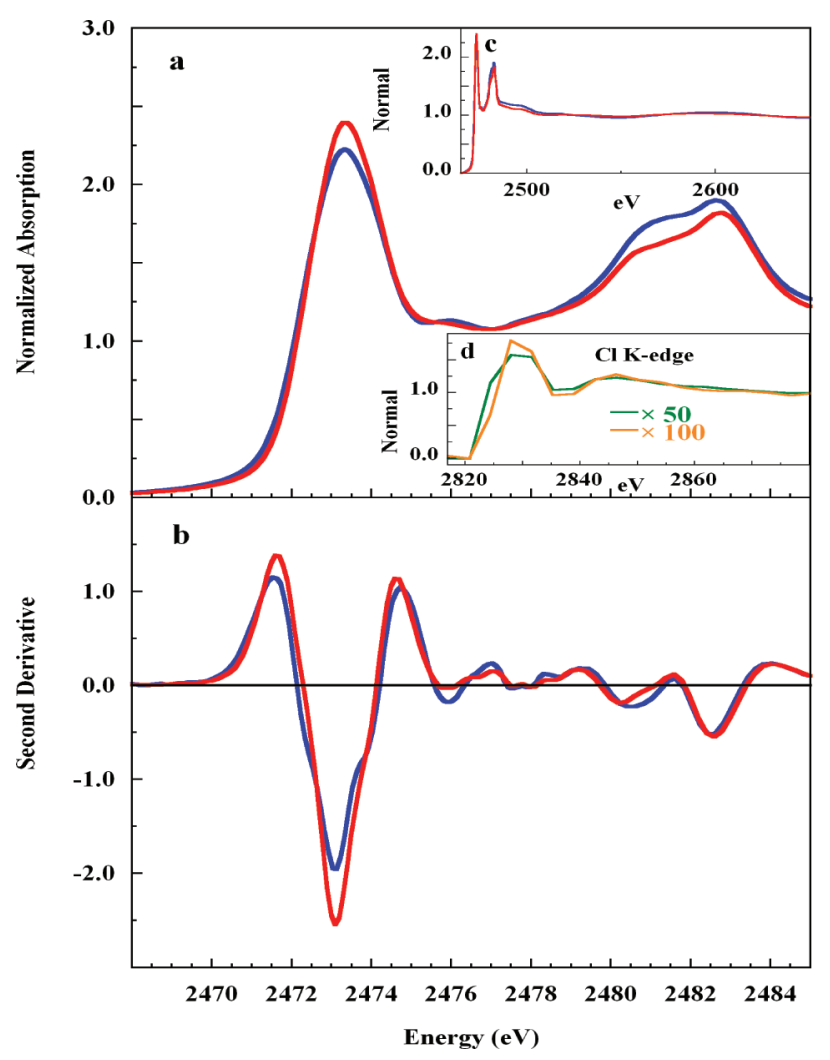

Figure 1. (a) Sulfur K-edge XAS spectra of (blue line) black wood and (red line) brown wood. (b) Second derivatives of the same XAS spectra (five-point-smoothed). (Inset c) Black wood and brown wood XAS spectra showing the parity of normalization. (Inset d) Renormalized $\mathrm{Cl}$ K-edge XAS spectra from (orange line) black wood and (green line) brown wood. the XAS spectra (Figure 1a,b) indicate compositional differences in sulfur valence and functional groups. Very weak $\mathrm{Cl} \mathrm{K}$ edges were found at $2820 \mathrm{eV}$, which could be extracted and renormalized (Figure 1d).

Sulfur K-Edge Analysis. The identity and distribution of sulfur functional groups within rostrum wood were assessed by numerical fits to the sulfur K-edge XAS spectra of the two wood samples using the XAS spectra of appropriate model compounds. ${ }^{6,16,18,19}$ Archeological wood is an infinite molecular lattice with a potentially large but unknown number of microenvironments for covalently bound sulfur. ${ }^{7,20}$ This is analytically important because sulfur K-edge XAS spectra are sensitive to modest variations in molecular structure, even at constant sulfur functionality (see Figure S3-1 in the Supporting Information). ${ }^{13,16,21}$ As exact structural analogues of the extended structural environments of lattice-bound sulfur will not be found in discrete small-molecule models, ${ }^{16}$ systematic error will enter any numerical fit to the XAS spectrum of latticebound sulfur.

Initial fits to the sulfur K-edge XAS spectra of rostrum wood indicated compositional complexity. Therefore, a piecewise approach was taken, beginning with fits to low-valent sulfur $\left(\mathrm{S}^{2-}\right.$ to $\left.\mathrm{S}^{3+}, 2460-2480 \mathrm{eV}\right)$. The intensity from the XAS of high-valent sulfur that subtends into this lower energy region was taken into account using a pseudo-Voigt line (HWHM = $0.72 \mathrm{eV}$ ), initially set at $2481 \mathrm{eV}$ and allowed to float in intensity and position. The functional group XAS spectra in a successful fit to low-valent sulfur were then ratioed into a single XAS spectrum and renormalized to unit continuum intensity. This composite low-valent sulfur K-edge XAS spectrum was then used in fits to the full sulfur K-edge XANES spectrum of rostrum wood $(2460-2485 \mathrm{eV})$.

Every fit was judged both by the goodness-of-fit $F$ and by detailed visual comparison of the measured and fitted XAS spectra and their second derivatives. Comparison of second derivatives is necessary because it reveals misalignments that are otherwise invisible in the fits. Figures S3-1 and S3-2 in the Supporting Information exemplify this necessity in that a definitive choice between alternative fits (di-tert-butyl disulfide vs L-cystine) was possible only following inspection of the fit second derivatives. Table S3-1 in the Supporting Information lists all the alternative functional groups tested in this manner.

Figure 2 shows the final fit to the low-energy region of the rostrum black wood sample using this strategy. As noted above, the composite fitted XAS spectrum of low-valent sulfur was used in the subsequent fits to the entire sulfur K-edge XAS spectrum of rostrum wood over the full $2460-2485 \mathrm{eV}$ energy range.

The sulfur XAS features observable at 2480.4 and $2482.5 \mathrm{eV}$ (Figure 1) typically imply organosulfonate ion and sulfate, respectively. The XAS spectrum of aqueous sulfate ion is $\mathrm{pH}$ dependent, ${ }^{16}$ and the XAS spectra of solution sulfate at both $\mathrm{pH} 0$ and $\mathrm{pH} 6.3$ were tested, even though the former condition was unlikely to be present after the flush with deionized water. In all combinations tested, the fit algorithm invariably rejected the XAS spectra of methanesulfonate ion, and of sulfate ion at either $\mathrm{pH}$, in favor of the XAS spectra of covalent organosulfate esters. Covalent sulfate esters are of lower symmetry than free sulfate ion, and the loss of orbital degeneracy produces more complex XAS spectra. ${ }^{16,19}$ Among these, the fits invariably favored the XAS spectrum of methyl sulfate over that of the similar alkyl monoester myo-inositol hexasulfate. 


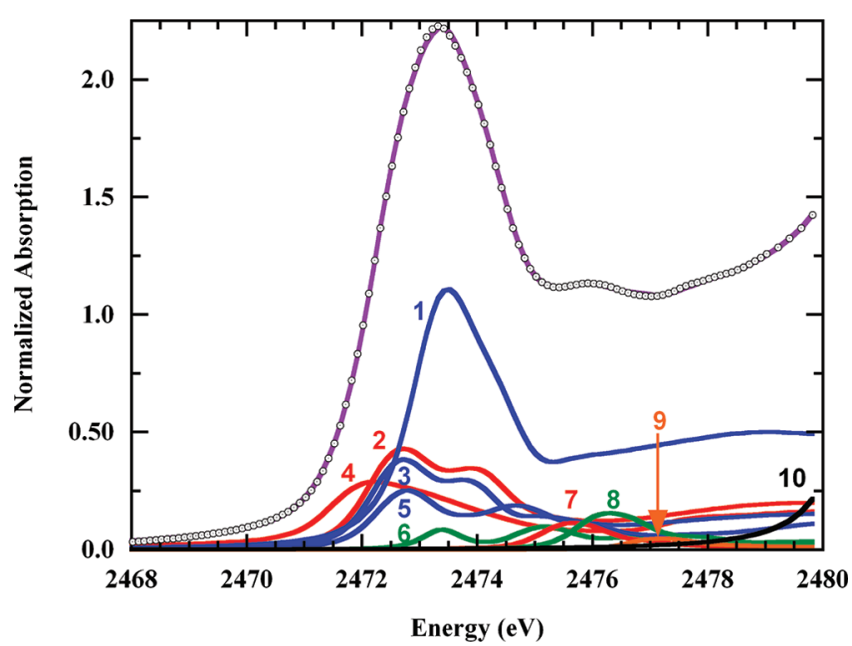

Figure 2. Fit to the K-edge XAS spectrum of low-valent sulfur in the rostrum black wood sample: (o) rostrum XAS data and (purple line) the fit. The sulfur components are (1) L-cysteine ( $\mathrm{pH} 7.1),(2) S$-(tertbutylthio)-L-cysteine, (3) di-tert-butyl disulfide, (4) pyrite, (5) 5,5'dithiobis(2-nitrobenzoate) ( $\mathrm{pH} 7.1$ ), (6) 2,1,3-benzothiadiazole, (7) trimethylsulfonium, (8) L-methionine sulfoxide, (9) L-cysteinesulfinate ( $\mathrm{pH}$ 8.5), and (10) the pseudo-Voigt high-valent sulfur XAS background.

The XAS spectra of four very different covalent sulfate esters were required to fit the high-valent sulfur feature. Three of these four were cyclic O,O-diesters (see Table S3-2 in the Supporting Information for the structures). Figure 3a shows the final fit to the rostrum black wood sample, along with the XAS spectra used to model high-valent sulfur. The second-derivative sulfur K-edge XAS spectrum of the rostrum black wood and of the fit appear in Figure $3 \mathrm{~b}$. Although the fit itself corresponds quite well to the data over the entire energy range, the second derivative shows misfits in the $2476-2479 \mathrm{eV}$ energy range, corresponding chiefly to the rising K-edges of sulfur of +2 to +4 valence (sulfoxides, sulfinates, sulfones, and sulfites). The
2476-2479 eV energy region also includes broad resonances of the continuum $1 \mathrm{~s} \rightarrow \psi^{*}$ transitions of lower valent sulfur (see Figure 2). ${ }^{22,23}$ In rostrum wood, these sulfur XAS features reflect single and multiple scattering from the potentials of unknown lattice structures. Thus, their reproduction is problematic. Nevertheless, the minimal structured intensity in the 2476-2479 eV energy region indicates that functional groups of intermediate sulfur valence are, at best, only minority species.

In addition, while the higher energy XAS feature of sulfate ester is well fit, the lower energy sulfate ester feature is less so. The latter feature probably represents the $1 \mathrm{~s} \rightarrow \sigma^{*}$ transition to an excited state that includes the (S-OR) antibonding orbital, where $\mathrm{R}$ represents the lattice. As with the disulfides, this transition is likely to be the more sensitive to structural disparities between the peculiar local framework of lattice carbon and the model compounds.

The fit to the sulfur K-edge XAS data of the rostrum brown wood sample followed an identical strategy, and the final fit is shown in Figure 4a. The respective XAS components of the low-valent and high-valent model spectra have been combined to show their total contributions (see Figure S3-3 in the Supporting Information for the full fit). In general, the brown wood XAS data were fit with nearly the same suite of model XAS spectra that fit the black wood XAS data, but in different proportions. Exclusion of $S$-(tert-butylthio)-L-cysteine from brown wood, in favor of increased thiol, pyrite, and elemental sulfur, represented a significant compositional difference. As with black wood, the best fits to the brown wood high-valent sulfur XAS data excluded the organosulfonate and free sulfate ions and accepted only the XAS spectra of sulfate esters.

The second derivatives of the brown wood XAS spectrum and the fit to the brown wood XAS spectrum are compared in Figure $4 \mathrm{~b}$. The fit to the XANES spectrum is good, but the second derivative again shows fit mismatches in the energy regions representing sulfur of intermediate valence and in the lower energy sulfate ester feature. The sulfur functional groups stemming from both final fits appear in Table 2. The specific

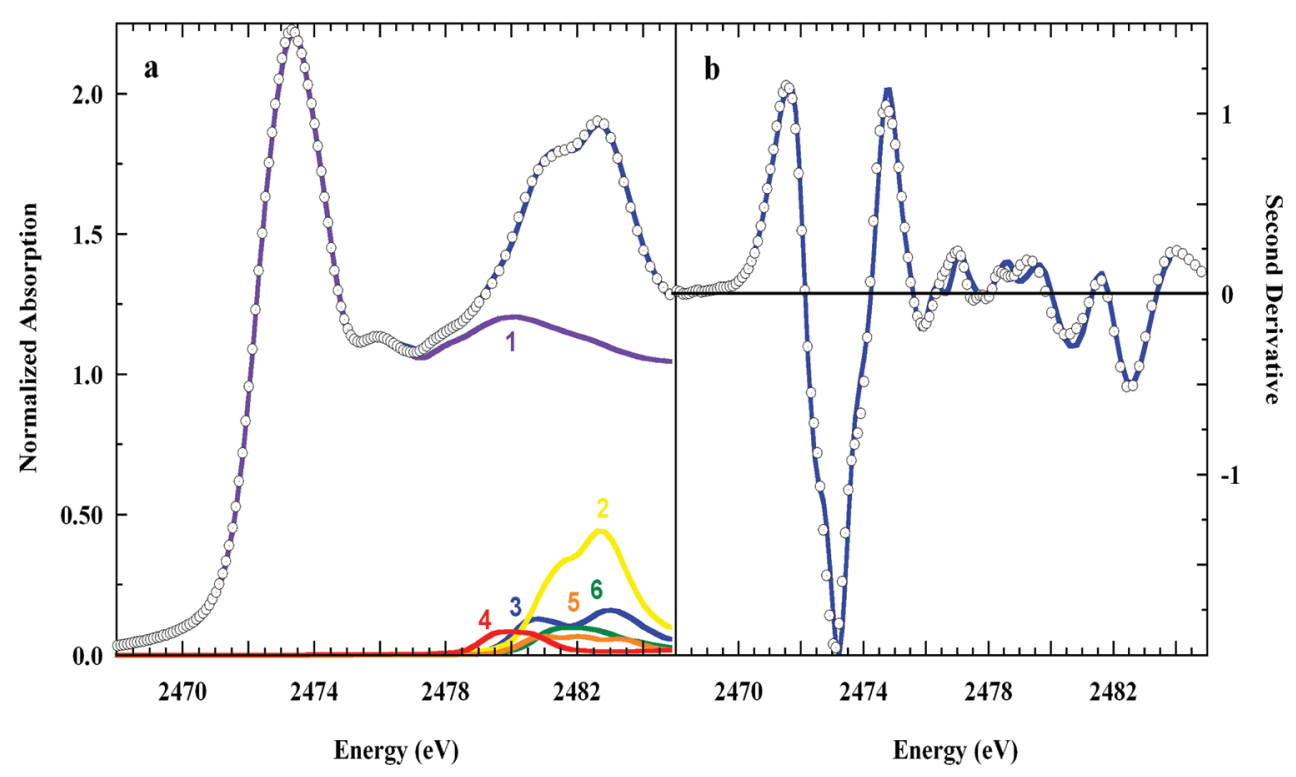

Figure 3. (a) (o) Sulfur K-edge XAS data of the rostrum black wood sample and (blue line) the fit. (b) Second derivatives of (o) the XAS spectrum and (blue line) the fit. In part a the fit components are (1) total low-valent sulfur (cf. Figure 2), (2) sodium methyl sulfate, (3) dimethyl L-tartrate 2,3-O-sulfate, (4) methionine sulfone, (5) 1,2:5,6-di-O-isopropylidene-D-mannitol-3,4-O-sulfate, and (6) 1,3-propylene cyclic sulfate. 


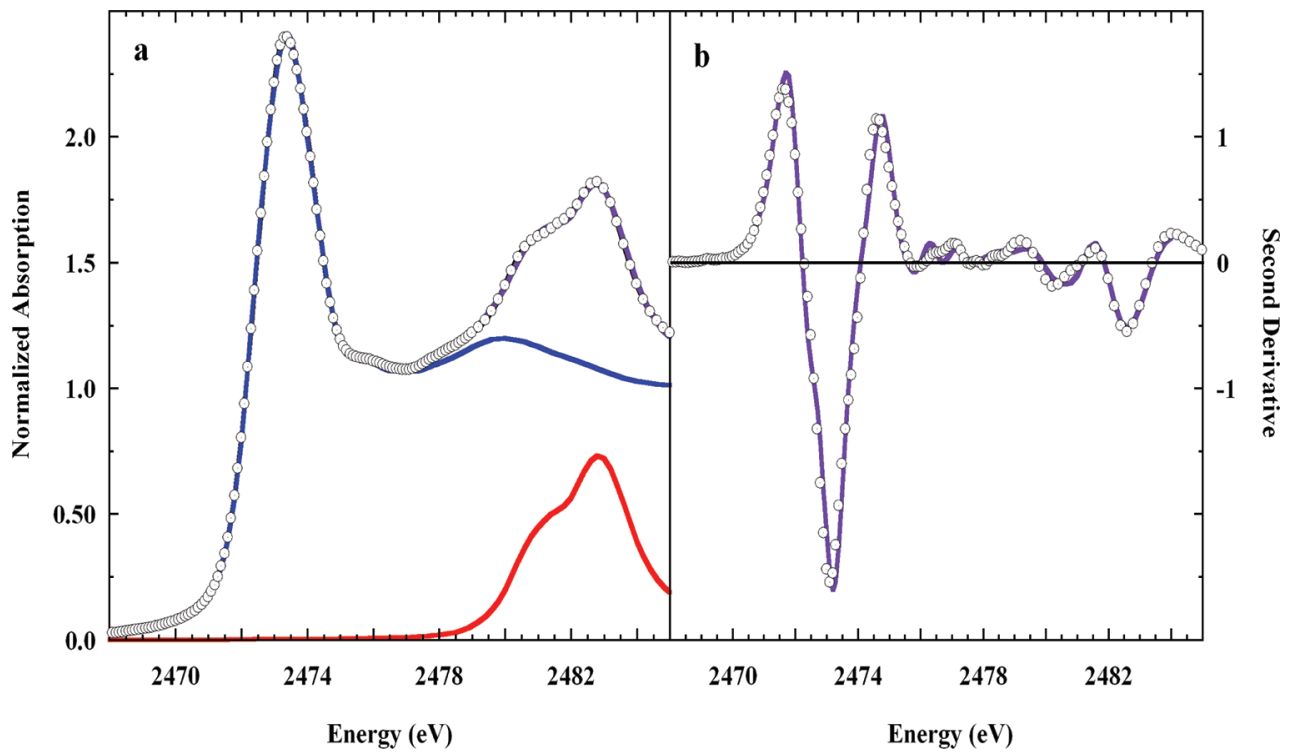

Figure 4. (a) (o) Sulfur K-edge XAS spectrum of the rostrum brown wood sample, (purple line) the fit to the spectrum, and the summed low-valent (blue line) and (red line), high-valent portions of the fit. (b) (o) Second derivative of the XAS spectrum of the rostrum brown wood sample and (purple line), the second derivative of the fit.

model compound XAS spectra entering into the fits are given in Table S3-2 of the Supporting Information.

The average systematic uncertainty in the accuracy of each fitted fraction was estimated as $F(\mathrm{se})= \pm\left(\sum_{\text {all fits }}[1-\right.$ (total fitted fraction $\left.)]^{2}\right)^{1 / 2}$, shown in Table 2 , where "total fitted

Table 2. Sulfur Functional Groups in the Acqualadrone Rostrum Wood

\begin{tabular}{|c|c|c|c|c|}
\hline component & $\begin{array}{l}\text { black wood } \\
(\%)\end{array}$ & \pm esd & $\begin{array}{l}\text { brown wood } \\
(\%)\end{array}$ & \pm esd \\
\hline$\alpha-\mathrm{S}_{8}$ & 2.1 & 0.4 & 6.4 & 0.4 \\
\hline $\mathrm{FeS}_{2}$ & 11.9 & 0.3 & 5.8 & 0.20 \\
\hline $\mathrm{R}-\mathrm{SH}$ & 33.2 & 0.4 & 43.0 & 0.3 \\
\hline $\mathrm{R}-\mathrm{S}-\mathrm{S}-\mathrm{R}(\mathrm{I})^{a}$ & 7.7 & 0.6 & 8.8 & 0.3 \\
\hline $\mathrm{R}-\mathrm{S}-\mathrm{S}-\mathrm{R}(\mathrm{II})^{b}$ & 18 & 2 & 0.00 & \\
\hline $\mathrm{R}-\mathrm{S}-\mathrm{S}-\mathrm{R}(\mathrm{III})^{c}$ & 6.0 & 1.4 & 17.5 & 0.8 \\
\hline$=\mathrm{N}-\mathrm{S}-\mathrm{N}=$ & 2.6 & 0.3 & 2.3 & 0.2 \\
\hline $\mathrm{R}_{3} \mathrm{~S}^{+}$ & 2.1 & 0.2 & 2.0 & 0.1 \\
\hline $\mathrm{R}_{2} \mathrm{~S}=\mathrm{O}$ & 2.3 & 0.1 & 1.4 & 0.1 \\
\hline $\mathrm{R}_{2} \mathrm{~S}(=\mathrm{O}) \mathrm{O}^{-}$ & 0.6 & 0.1 & 0.8 & 0.1 \\
\hline $\mathrm{R}_{2} \mathrm{~S}(=\mathrm{O})_{2}$ & 1.6 & 0.1 & 0.5 & 0.1 \\
\hline $\mathrm{R}-\mathrm{OSO}_{3}^{-}$ & 5.6 & 0.6 & 2.7 & 0.5 \\
\hline cyclo- $\mathrm{R}(\mathrm{O})_{2} \mathrm{~S}(=\mathrm{O})_{2}(\mathrm{I})^{d}$ & 1.5 & 0.6 & 1.8 & 0.4 \\
\hline $\begin{array}{l}\text { cyclo-R } \\
\text { (II })^{d}\end{array}$ & 2.8 & 0.4 & 4.3 & 0.2 \\
\hline$\underset{(\mathrm{III})^{d}}{\text { cyclo-R }^{d}(\mathrm{O})_{2} \mathrm{~S}(=\mathrm{O})_{2}}$ & 1.2 & 0.5 & 0.0 & 0.0 \\
\hline sodium jarosite & 0.00 & & 2.6 & 0.3 \\
\hline low-valent total & 86.8 & & 87.6 & \\
\hline high-valent total & 13.2 & & 12.4 & \\
\hline$F$ value $( \pm 1 \sigma)^{e}$ & $8.7 \times 10^{-5}$ & & $4.0 \times 10^{-5}$ & \\
\hline$F(\mathrm{se})^{f}$ & $\pm 12 \%$ & & $\pm 10 \%$ & \\
\hline
\end{tabular}

${ }^{a_{5,5}}$-Dithiobis(2-nitrobenzoate) in aqueous $\mathrm{pH} 7.1$ buffer representing a polar oxidized aromatic environment. ${ }^{b}$ Semipolar environment represented by $S$-(tert-butylthio)-L-cysteine in aqueous $\mathrm{pH} 7.1$ buffer. ${ }^{c}$ Nonpolar environment represented by bis-tert-butyl disulfide in $p$ xylene. ${ }^{d}$ Cyclic sulfate diester; for structures see Table S3-2 in the Supporting Information. ${ }^{e}$ Statistical goodness-of-fit. ${ }^{f}$ Average fit fraction systematic error. fraction" is the sum of the component fractions in each fit. See section 4.2 in the Supporting Information for a more extended discussion of $F(\mathrm{se})$.

Cl K-edge features of very low intensity were evident near $2821 \mathrm{eV}$ in the XAS spectrum of both rostrum wood samples (Figure 1d). These were extracted and renormalized to unit intensity. The low resolution and the impact of the underlying sulfur XAS spectrum do not allow any distinction of ionic or covalent $\mathrm{Cl}$. Assuming the $\mathrm{Cl}$ transition probability is equal to that of sulfur, $\sim 900 \mathrm{ppm} \mathrm{Cl}$ could be estimated for black wood and $\sim 400$ ppm for brown wood.

GC/MS and Pyrolysis. The mobile and thermalizable organic compounds present in black rostrum wood were examined by chemical treatment or pyrolysis followed by GC/ MS. Analytes were identified by direct comparison with commercial reference materials (from Belgium, France, Germany, and The Netherlands) available at the Belgium Royal Institute for Cultural Heritage, KIK-IRPA, by use of a customized digital library (based on the NIST library), and by interpreting the corresponding mass spectra. Figure 5 shows a typical GC/MS chromatogram of the extractable compounds, which are identified in Table 3. Some of these organics are markers for a resin from Pinaceae spp. For example, the derivatives of pimaric acid and phenanthrene descend from abietic acid, a major component of pine resin. ${ }^{24,25}$

The GC traces resulting from pyrolysis of rostrum wood are shown in Figures 5 and 6. In Figure 6, the intense 3,4dimethoxytoluene peak at $3.09 \mathrm{~min}$ and the rich presence of veratraldehyde $(3.77 \mathrm{~min})$ and veratric acid $(4.12 \mathrm{~min}$ ) are sufficient to distinguish the pyrolysis of pine from oak. ${ }^{26}$ The high-molecular-weight pyrolysis products, Figure 7, again indicate pine resin, including sandaracopimaric and abietic acids and their derived forms. ${ }^{2,26,27}$

In the pyrograms, the relative intensities of the resin peaks are high compared to those from lignin pyrolysis alone (e.g., mono- and dimethoxybenzene and their oxidized forms, eluted before $6 \mathrm{~min})$. Although the wooden part of the rostrum consists of pine wood, the very high presence of resin acids (dehydroabietic acid, norabietane), their derived forms, and the 


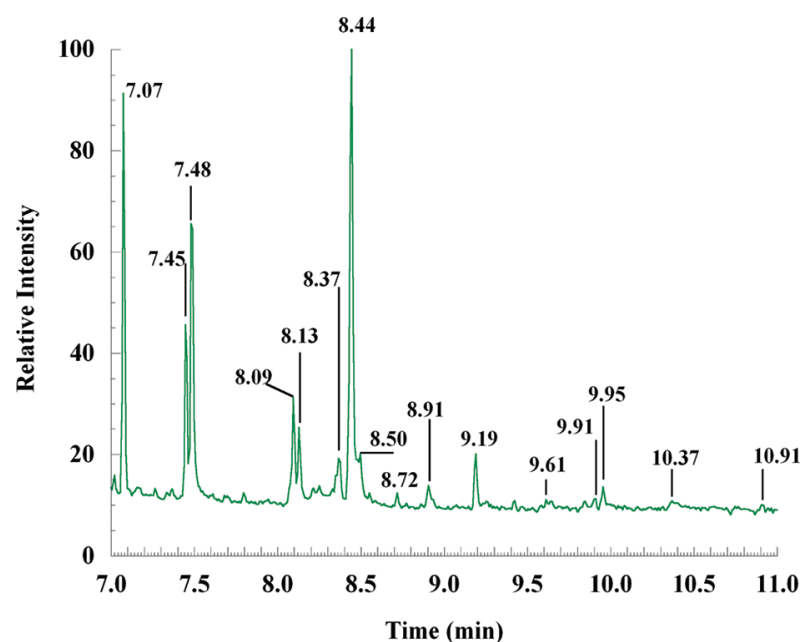

Figure 5. Typical GC trace showing mobile organic materials obtained from extraction and derivatization of the black Acqualadrone rostrum sample, extracted using alkaline methanolic toluene. Peaks are labeled with retention times. All the peaks of retention time $\leq 6.5 \mathrm{~min}$ originated from materials used for sample preparation and derivatization. The major eluted fractions were $4 b, 5,6,7,8,8 a, 9,10$ octahydro-4b,8-dimethyl-2-isopropylphenanthrene at $7.07 \mathrm{~min}$ and methylpimaran-18-oate at $8.44 \mathrm{~min}$. See Table 3 for the peak assignments.

presence of unidentified polycyclic aromatic and aliphatic hydrocarbons (in both analyses) are evidence that a pinederived pitch had been spread onto the wood as a caulking

Table 3. GC Data of the Black Wood Mobile Organics

\begin{tabular}{|c|c|c|}
\hline $\begin{array}{l}\text { retention time } \\
(\mathrm{min})\end{array}$ & $\begin{array}{l}\text { identified compd (IUPAC and common name, } \\
\text { where available) }\end{array}$ & $\begin{array}{c}\text { rel } \\
\text { intens }\end{array}$ \\
\hline 3.10 & from the derivatization agent & 0.38 \\
\hline 3.16 & from the derivatization agent & 0.38 \\
\hline 3.20 & siloxane & 0.32 \\
\hline 3.55 & from the derivatization agent & 0.26 \\
\hline 3.59 & from the derivatization agent & 1.00 \\
\hline 3.70 & from the derivatization agent & 0.24 \\
\hline 4.04 & $\begin{array}{l}\text { dimethyl benzene-1,2-dicarboxylate (dimethyl } \\
\text { phthalate) }\end{array}$ & 0.92 \\
\hline 4.43 & benzene-1,2-dicarboxylate ester (phthalate) & 0.29 \\
\hline 4.78 & benzene-1,2-dicarboxylate ester (phthalate) & 0.37 \\
\hline 6.21 & from the derivatization agent & 0.20 \\
\hline 6.52 & methyl hexadecanoate (methyl palmitate) & 0.51 \\
\hline 6.94 & possibly 18-norabietane & 0.16 \\
\hline 6.98 & a structural isomer of androstane & 0.41 \\
\hline 7.07 & $\begin{array}{l}\text { 4b,5,6,7,8,8a,9,10-octahydro- } 4 \mathrm{~b}, 8 \text {-dimethyl-2- } \\
\text { isopropylphenanthrene }\end{array}$ & 0.81 \\
\hline 7.45 & 3,4'-diisopropylbiphenyl & 0.41 \\
\hline 7.48 & methyl octadecanoate (methyl stearate) & 0.59 \\
\hline 8.09 & a structural isomer of methylpimar-7-en-18-oate & 0.28 \\
\hline 8.13 & a structural isomer of methylpimar-7-en-18-oate & 0.23 \\
\hline 8.37 & unidentified from sandarac & 0.17 \\
\hline 8.44 & methylpimaran-18-oate & 0.89 \\
\hline 8.50 & $\begin{array}{l}\text { methyl abieta-8,11,13-trien-18-oate (methyl } \\
\text { dehydroabietate) }\end{array}$ & 0.18 \\
\hline 8.72 & methyl abieta-7,13-dien-18-oate (methyl abietate) & 0.11 \\
\hline 8.91 & unidentified from pine resin & 0.12 \\
\hline 9.19 & unidentified from pine resin & 0.18 \\
\hline 9.95 & methyl tetracosanoate (methyl lignocerate) & 0.12 \\
\hline $10.37,10.91$ & unidentified & \\
\hline
\end{tabular}

Figure 6. GC trace of the early emerging lignin pyrolytic volatiles released from the black sample of Acqualadrone rostrum wood. Peaks are labeled with retention times. The dominant peaks at 3.09 and 3.77 min represent 3,4-dimethoxytoluene and 3,4-dimethoxybenzaldehyde, respectively. See Table 4 for the peak assignments.

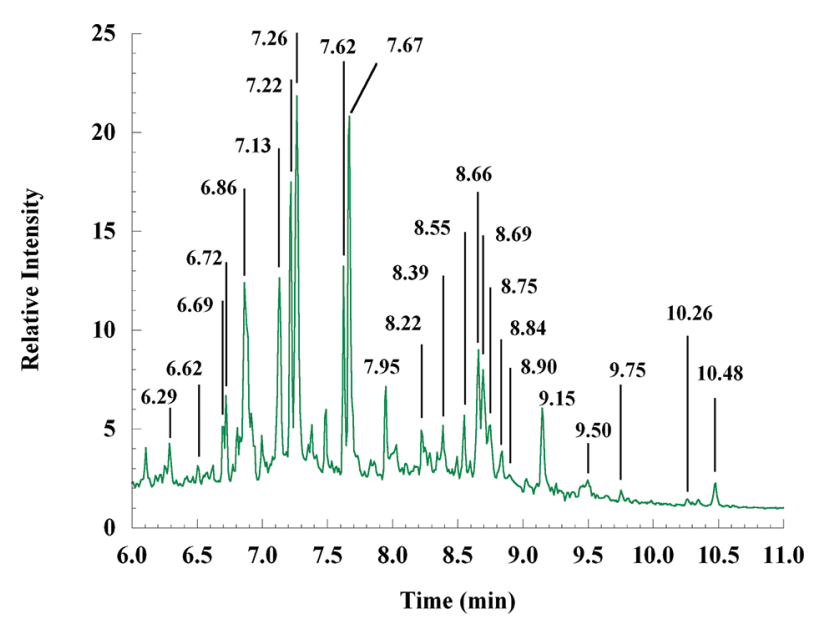

Figure 7. GC trace of the late-emerging pyrolytic volatiles released from the Acqualadrone rostrum black wood sample. The ordinate intensity scale is expanded relative to that of Figure 6. Peaks are labeled with retention times. The unidentified intense peaks at 7.26 and $7.67 \mathrm{~min}$ are typical of pine resin. See Table 4 for the peak assignments.

material. ${ }^{28}$ It is known that various polycyclic hydrocarbons are created in the production of pitch from the decarboxylation, dehydrogenation, and demethylation of the above-mentioned pine resin acids. ${ }^{25,29}$

Lignoceric (C24:0) and behenic (C22:0) acids (Table 4) are known to arise from plants. Blank scans showed contamination by phthalates and stearic and palmitic acids (Figure 5). The absence of any long-chain $n$-alkanes such as heptacosane $\left(\mathrm{C}_{27} \mathrm{H}_{56}\right)$ excludes a beeswax caulk. ${ }^{30}$

\section{DISCUSSION}

Gas chromatography/mass spectrometry and sulfur K-edge Xray absorption spectroscopy have been combined to examine the wood of the Aqualadrone military rostrum, dating to the First Punic War. The extractable and pyrolytic volatiles together establish the rostrum to have been constructed of pinewood and waterproofed with pine pitch. K-edge XAS speciation of the 


\section{Table 4. GC Data of the Black Wood Pyrolytic Volatiles}

\begin{tabular}{|c|c|c|}
\hline $\begin{array}{l}\text { retention time } \\
(\mathrm{min})\end{array}$ & $\begin{array}{l}\text { identified compd (IUPAC and common name, } \\
\text { where available) }\end{array}$ & $\begin{array}{c}\text { rel } \\
\text { intens }\end{array}$ \\
\hline 3.09 & 3,4-dimethoxytoluene (4-methylveratrole) & 1.00 \\
\hline 3.17 & 4-methoxybenzaldehyde (4-anisaldehyde) & 0.08 \\
\hline 3.30 & 4-ethyl-1,2-dimethoxybenzene & 0.14 \\
\hline 3.44 & 4-ethenyl-1,2-dimethoxybenzene & 0.49 \\
\hline 3.77 & 3,4-dimethoxybenzaldehyde (veratraldehyde) & 0.70 \\
\hline 3.82 & 4-allyl-1,2-dimethoxybenzene (methyleugenol) & 0.15 \\
\hline 4.04 & 2,4-dimethoxyacetophenone & 0.15 \\
\hline 4.12 & methyl 3,4-dimethoxybenzoate (methyl veratrate) & 0.54 \\
\hline 4.23 & $\begin{array}{l}\text { methyl (3,4-dimethoxyphenyl)acetate (methyl } \\
\text { homoveratrate) }\end{array}$ & 0.19 \\
\hline 4.29 & 2,5-dimethoxy-4-ethylbenzaldehyde & 0.14 \\
\hline 5.27 & $\begin{array}{l}\text { methyl (E)-3-phenylprop-2-enoate (methyl } \\
\text { cinnamate) }\end{array}$ & 0.08 \\
\hline 6.11 & unidentified $\mathrm{PAH}^{a}$ & 0.04 \\
\hline 6.86 & $\begin{array}{l}\text { methyl 13-methyl-17-norabieta-8(14),15-dien-18- } \\
\text { oate (methyl sandaracopimarate) }\end{array}$ & 0.12 \\
\hline 7.13 & $\begin{array}{l}\text { fragment from methyl abieta-7,13-dien-18-oate } \\
\text { (methyl abietate) }\end{array}$ & 0.13 \\
\hline 7.22 & methyl abieta-18-oate (methyl tetrahydroabietate) & 0.17 \\
\hline 7.26 & unidentified from pine resin & 0.17 \\
\hline 7.49 & methyl abieta-7,13-dien-18-oate (methyl abietate) & 0.06 \\
\hline 7.67 & unidentified from pine resin & 0.21 \\
\hline 7.95 & methyl docosanoate (methyl behenate) & 0.07 \\
\hline 8.22 & $\begin{array}{l}\text { methyl 13-isopropyl-7-oxopodocarpa-8,11,13-trien- } \\
\text { 18-oate (methyl 7-oxodehydroabietate) }\end{array}$ & 0.05 \\
\hline 8.66 & $\begin{array}{l}\text { fragment from methyl 13-methyl-17-norabieta- } \\
8(14), 15 \text {-dien-18-oate (methyl } \\
\text { sandaracopimarate) }\end{array}$ & 0.09 \\
\hline 8.69 & methyl tetracosanoate (methyl lignocerate) & 0.08 \\
\hline $8.75-10.48$ & unidentified & \\
\hline
\end{tabular}

endogenous sulfur revealed the copious reduced species consistent only with long-term anoxic burial and colonization by sulfate-reducing bacteria. $8,11,19,31$

This study has also introduced a general estimate of average systematic error in XAS speciations, as $F($ se $)= \pm\left(\sum_{\text {final fits }}[1\right.$ $-($ total fitted fraction $\left.)]^{2}\right)^{1 / 2}$, which provides an objective measure of accuracy in the numerical fits. A major source of systematic error affecting the accuracy of XAS speciations is the accumulation of small errors in XAS spectra during baseline subtraction and normalization. See sections 2 and 4 in the Supporting Information for further discussion on this point. Systematic errors in fits also arise from disparities between the structure of sulfur functional group models and the unknown structure around sulfur functional groups in a sample. These produce mismatches in energy positions and intensities in the fitted feature, which in turn propagate errors into other fitted fractions because of intensity overlaps. The problem is exacerbated by the multifarious structural environments likely to typify any given lattice-bound sulfur functional group.

Self-absorption broadening of solid models such as pyrite can also introduce errors in fractional fits. ${ }^{32}$ However, the particle size of pyrite in marine archeological wood is $\sim 25 \mu \mathrm{m},{ }^{31}$ while the $1 / e$ attenuation length of pyrite is $\sim 0.9 \mu \mathrm{m}$ at its rising sulfur K-edge $(2473 \mathrm{eV})$. The sulfur K-edge XAS spectrum of rostrum pyrite is thus likely to be broadened from intrinsic selfabsorption. However, particle sizes of about $25 \mu \mathrm{m}$ can be achieved using an agate mortar and pestle. ${ }^{33,34}$ Therefore, use of the self-absorption broadened XAS spectrum of a solid pyrite model does not necessarily introduce an error into fitted fractions. In this light, solid samples of varying particle size might be used to make a library of sulfur K-edge XAS spectra that are systematically self-absorption broadened. This library could be employed for nondestructive estimates of the average particle size of pyrites or other solid sulfur species in samples of archeological or environmental interest. ${ }^{35}$

When an unknown material is a mixture of discrete molecules only, one may achieve high accuracy in an XAS functional group speciation experiment. However, in an analysis of lattice-bound sulfur and including the systematic errors noted above, the average accuracy of a fit, $F($ se), will probably never be better than about $\pm 10 \%$. Nevertheless, choosing the appropriate sulfur functional group XAS model itself is almost entirely unambiguous, because the uniquely distinct XAS spectra of the alternatives makes an incorrect choice immediately obvious. ${ }^{13,16,18,19,21}$

The sulfur K-edge XAS spectrum of dimethyl sulfoxide (DMSO) was recently proposed as an internal calibrant to ensure the accurate sulfur K-edge XAS intensity of any soluble model compound. ${ }^{36-38}$ The originators of this method appear not to have realized that XAS spectra suffering from selfabsorption exhibit broadening as well as intensity suppression. Rescaling the intensity does not remove the distortion due to broadening. ${ }^{35,39}$

Moreover, propagation of error through the internal calibration method shows that it increases, not decreases, the uncertainty in the intensity of recalibrated XAS spectra (see section 4.1 in the Supporting Information). The reason is that each XAS spectrum must be independently baseline corrected and normalized. This process introduces a unique, though small, systematic error into every XAS spectrum. This systematic error propagates up into the final intensity of any sum, difference, product, or ratio of multiple XAS spectra. ${ }^{40}$

More formally, the intensity of any normalized XAS spectrum, $I_{\text {norm }}$ can be represented as the intrinsic intensity, $I_{0}$, plus the sum of random and systematic errors:

$$
I_{\text {norm }}=I_{0}+\varepsilon_{\text {ran }}+\varepsilon_{\text {sys }}
$$

The total uncertainty in the intensity of any normalized measured XAS scan, $\pm \sigma_{\text {norm }}$ is thus ${ }^{40}$

$$
\pm \sigma_{\text {norm }}= \pm \sqrt{\varepsilon_{\text {ran }}^{2}+\varepsilon_{\text {sys }}^{2}}
$$

The process-related systematic errors that enter into an XAS spectrum during baseline subtraction and normalization are unique to each XAS spectrum and are in addition to any systematic effects arising from the sample, such as selfabsorption, ${ }^{32}$ or from the X-ray spectrophotometer. However, the $\mathrm{S} / \mathrm{N}$ of any standard sulfur K-edge XAS spectrum is typically very high (ca. 500-1500; cf. sections 2 and 4 in the Supporting Information). Therefore, the final normalized intensity of the XAS spectrum of any properly made standard model solution is likely to be as accurate as the normalized intensity of the K-edge XAS spectrum of any calibration solution.

To show the effect of an added internal calibration step following from eq 2, any DMSO internal calibration XAS spectrum will include its own unique systematic error, $\pm \sigma_{\mathrm{cal}}$, after baseline subtraction and normalizion. The K-edge XAS spectrum of any pure model compound, to be recalibrated and used as a standard for numerical fits, will also have its own unique initial level of systematic error, $\pm \sigma_{\text {norm }}^{\text {ini }}$ after baseline subtraction and normalization. Rescaling the intensity of the 
standard model compound XAS spectrum using the XAS calibration spectrum propagates $\pm \sigma_{\mathrm{cal}}$ into $\pm \sigma_{\text {norm }}^{\mathrm{ini}}$. The final uncertainty in the intensity of the XAS standard is the convolution of the two uncertainties and $\pm \sigma_{\text {renorm }}^{\text {final }}= \pm\left(\left(\sigma_{\text {norm }}^{\text {ini }}\right)^{2}\right.$ $\left.+\sigma_{\text {cal }}^{2}\right)^{1 / 2}$. The total uncertainty in the intensity of the calibrated standard sulfur XAS spectrum is thus increased over what it would have been without the calibration step. See section 4.1 in the Supporting Information for a full derivation of this result.

The only rationale for an internal calibration is if $I_{\text {norm }}$ cannot be determined directly or if it is known that $\sigma_{\text {norm }} \gg \sigma_{\text {cal }}$. However, as noted above, the solution XAS spectra of both the calibration DMSO and of the standard model will typically include very high $\mathrm{S} / \mathrm{N}$ and can be processed through to normalization with equivalent accuracy. Therefore, no advantage is obtained by internal intensity calibrations of standard model XAS spectra.

Although chloride and sulfate dominate in seawater, ${ }^{41,42}$ no evidence of free inorganic sulfate ion was found in rostrum wood and only traces of chloride. It appears the flowpreservation scheme washed out all the soluble ions. While significant concentrations of iron, copper, and zinc remained, the high likelihood of material loss should discourage any metallurgical deductions.

Sulfur in rostrum wood is similar in concentration (mass \%) to that found in the archeological ships Vasa and Mary Rose $e^{6,11}$ and is likewise dominated by thiols and disulfides. MicroXANES studies of wood from the Vasa and the Mary Rose revealed reduced sulfur predominantly in lignin-containing lamina within the cellulosic lattice. ${ }^{8,11}$ Copious reduced sulfur in marine archeological wood necessarily indicates both longterm anoxic burial and colonization by sulfate-reducing bacteria. Rostrum wood falls into this category.

The unequal distributions of sulfur and pyrite in black wood and brown wood, $(2.1+11.9) \%$ and $(6.4+5.8) \%$, respectively, imply that brown wood experienced the more oxidizing environment and became more permeable. The brown wood also exhibited less copper and zinc and only about half the chloride found in black wood.

None of the three disulfide models are biologically realistic. However, they are suggestive of distinct chemical environments. The electron-deficient sulfur atoms of aqueous 5,5'dithiobis(2-nitrobenzoate) ${ }^{43}$ model a conjugated electrondeficient disulfide in a water-rich wood-lattice environment. Alternatively, aqueous $S$-(tert-butylthio)-L-cysteine models a saturated aliphatic disulfide in a semiaqueous lattice environment, and di-tert-butyl disulfide represents a lipophilic chemical environment. These imply microenvironments ranging from heavily degraded aqueous polar to more lightly degraded nonpolar ligneous. The intermediate environment modeled by aqueous $S$-(tert-butlythio)-L-cysteine in black wood is absent in brown wood.

The thiadiazole functionality is biologically rare, and only dendrodoine, a 1,2,4-thiadiazole from the solitary marine ascidian Dendrodoa grossularia, ${ }^{44}$ has been reported. Alternative but related sulfur model compounds with $\mathrm{N}-\mathrm{S}$ functionality, such as thiamine, 3,3'-diethylthiacyanine, and thiobisphthalimide, produced significantly inferior fits. Therefore, while the preference of the 2,1,3-benzothiadiazole fit model was apparent, a plausible origin for this unusual sulfur functional group is not available.

The trimethylsulfonium fraction may be direct evidence of bacterial 3-(dimethylsulfonio)propionate. This ubiquitous osmolyte is released by marine algae ${ }^{45}$ and taken up as a carbon or sulfur source by many bacteria, including anaerobes. ${ }^{45-47}$ Its presence at about $2 \%$ of the total sulfur $(\sim 800$ ppm) represents a very large amplification over the typical marine nanomolar concentrations. ${ }^{47}$ Trialkylsulfonium has not been reported in other bacterially colonized wooden archeological marine artifacts or in marine sediments. In rostrum wood, the presence of this cation despite the water flush is suggestive of either a cryptic residence or a covalent attachment.

The high concentration of sulfate esters $\left(\sim 4 \times 10^{3} \mathrm{ppm}\right)$ precludes an origin in pine wood, ${ }^{8,48}$ and the anoxic condition of burial defeats an oxidative explanation. However, sulfotransferases nonoxidatively convert organic hydroxyls into sulfate esters. ${ }^{49}$ Sulfotransferase activity has been found in the marine aerobe Pseudoalteromonas, resident in the gut of mollusks. ${ }^{50-52}$ Sulfotransferases are also reported in marine microalgae and phototropic bacteria, ${ }^{53}$ but not in marine anaerobes. Sulfate esters can also represent up to $\sim 25 \%$ of the sulfur in marine sediments, ${ }^{54}$ although their origin remains cryptic. It is difficult to conceive that the sulfate esters diffused into rostrum wood from local marine sediments, and thus, it seems most likely they resulted from sulfotransferase activity of as-yet-unspecified marine bacteria. ${ }^{50}$

Natrojarosite, $\left[\mathrm{NaFe}_{3}\left(\mathrm{SO}_{4}\right)_{2}(\mathrm{OH})_{6}\right]$, detected in brown wood but not black wood, is known to precipitate from ironand sulfate-rich waters under acidic conditions, ${ }^{55,56}$ possibly assisted by bacteria. ${ }^{57}$ If confirmed, endogenous natrojarosite would imply regions of $\mathrm{pH} \approx 1.5-3$ within the wood during anoxic burial.

The rostrum of the Acqualadrone ram is identified as pine rather than oak by the presence of abietic acid and 7oxodehydroabietic acid and with guaiacyl derivatives in the pyrolysis products concomitantly with the absence of syringic acid and syringaldehyde. ${ }^{26,30,58}$ The same distinction holds true for the detection of sandaracopimaric acid, which is absent from oak wood pyrolysis products. Although sandaracopimaric acid is also found in juniper wood, GC analysis of the methanolic extracts from the rostrum did not reveal any isocupressic acid or other similar diterpene acids that are more specifically diagnostic of juniper. ${ }^{59}$ Pine wood is known to have been extensively used for the construction of maritime ships in ancient Rome. ${ }^{60}$ However, the Acqualadrone military ram is the first to reveal structural pine in the rostrum. ${ }^{3}$

Relative to the pyrolysis products from lignin, such as the methoxybenzene derivatives, the intensities of resin acids and of polycyclic aromatic and aliphatic hydrocarbons are higher than expected for native pine wood (see Figure S3-4 in the Supporting Information for the full pyrogram). This excess indicates that the wood was waterproofed by treatment with pine pitch. Ancient maritime caulking is known to possibly contain beeswax, ${ }^{25}$ but the absence of long-chain $n$-alkanes excludes their use here.

The black wood sample was nearly 6 -fold richer in both iron and copper, though with a similar $\sim 1: 1.1$ overall iron-to-copper ratio (Table 1). The mass ratios of sulfur and iron are comparable to the elevated levels found in the archeological timbers of the Reformation-period marine shipwrecks Mary Rose and Vasa. ${ }^{6,11}$ The presence of iron, copper, and reduced sulfur means a sulfuric acid threat exists for the Acqualadrone rostrum. ${ }^{6,7,9}$ If the measured elemental sulfur and pyrite are representative, then about $14 \mathrm{~g}$ of sulfuric acid could emerge per kilogram of wet wood. 
While not previously considered in this context, it seems likely that rostrum copper may join iron in catalyzing production of sulfuric acid. Copper participates in Fenton chemistry $^{61}$ and catalyzes the Fenton chemistry of iron. ${ }^{62}$ Cupric ion also catalyzes the oxidation of aqueous sulfide ${ }^{63}$ and of thiols to disulfides. ${ }^{64}$ However, the copious presence of organosulfate esters leads to a further hypothesis. Autoxidation of thiols typically proceeds only as far as sulfonic acids. ${ }^{64-67}$ Conversion of pendant organosulfonates to sulfate esters requires oxygen atom insertion into the $\mathrm{C}-\mathrm{S}$ bond, which may be achieved by ozone. ${ }^{68,69}$ Under acidic conditions, sulfate esters can rapidly hydrolyze to produce further bisulfate ion, ${ }^{70}$ a reaction possibly catalyzed by $\mathrm{Cu}(\mathrm{II}) .^{71}$ Conversion of thiols to bisulfate through an organosulfate ester intermediate, by the action of ambient ozone and transition-metal ions, may be a further source of the acid found in air-exposed archeological wood. Removal of ozone from the ambient air within museums might help reduce the sulfuric acid threat.

In summary, this study has characterized the strutwork of the Acqualadrone rostrum as pinewood, water-proofed with pine pitch. Copious sulfur is present, along with high concentrations of iron, copper, and zinc. Sulfur K-edge XAS indicated multiple sulfur functionalities of low and high oxidation state and provided direct evidence of extensive colonization by sulfatereducing bacteria. The large concentration of reduced sulfur also puts the Acqualadrone rostrum into the class of archeological marine wood treasures that face a sulfuric acid threat. Finally, the Acqualadrone rostrum has clearly undergone a complex history never anticipated by its manufacturers.

\section{ASSOCIATED CONTENT}

\section{S Supporting Information}

Section 1, Estimate of signal to noise (S/N) in XAS spectra (Figures S1, S2); Section 2, normalization of XAS spectra for numerical fits (Figures S2-1 to S2-5); Section 3, Table S3-1 listing the substructures tested for sulfur functional group specificity and Table S3-2 listing the models used to fit the sulfur K-edge XAS of the Acqualadrone rostrum wood, Figure S3-1 and S3-2 showing the low-energy region of the sulfur Kedge XAS spectra, Figure S3-3 the full fit to Acqualadrone brown wood, Figure S3-4 full pyrogram of black wood from the Acqualadrone rostrum; Section 4, lack of utility of internal intensity calibration of XAS spectra assessed by propagation of error, methodological accuracy in normalization (Figure S4-1); description of the accuracy measure of numerical fits, $F(s e)$, numerical output Table 4-1. This material is available free of charge via the Internet at http://pubs.acs.org.

\section{AUTHOR INFORMATION}

\section{Corresponding Author}

*E-mail: pfrank@slac.stanford.edu.

\section{Present Address}

${ }^{\perp}$ Institut für Baustoffe (IfB), ETH Zürich, 8093 Zürich, Switzerland.

\section{Notes}

The authors declare no competing financial interest.

\section{ACKNOWLEDGMENTS}

We thank Sebastiano Tusa and Philippe Tisseyre from the Soprintendenza del Mare, Regione Siciliana, for providing the XAS samples and Steven Saverwyns and Marina Van Bos, KIKIRPA, for their technical assistance with the GC/MS measure- ments. We also thank Dr. Ritimukta Sarangi for her very constructive critical interest in this work. This work was supported by grant NIH RR-01209 (to Keith O. Hodgson and Britt Hedman, SLAC, Stanford University). Portions of this research were carried out at the Stanford Synchrotron Radiation Lightsource, a Directorate of SLAC National Accelerator Laboratory and an Office of Science User Facility operated for the U.S. Department of Energy Office of Science by Stanford University. The SSRL Structural Molecular Biology Program is supported by the DOE Office of Biological and Environmental Research, and by the National Institutes of Health, National Institute of General Medical Sciences (including P41GM103393) and the National Center for Research Resources (P41RR001209). The contents of this publication are solely the responsibility of the authors and do not necessarily represent the official views of NIGMS, NCRR or NIH.

\section{REFERENCES}

(1) Gini, G. Ritrovamento di un Rostro di Epoca Romana nelle Acque di Capo Rasocolmo/Acqualadroni Soprintendenza del Mare. http://www.regione.sicilia.it/beniculturali/archeologiasottomarina/ sez eventi/rostro messina.htm (accessed March 28, 2012).

(2) Romagnoli, M.; Spina, S.; Santamaria, U.; Caponetti, E.; Caruso, F.; Spinella, A.; Fedi, M.; Caforio, L.; Tusa, S.; Tisseyre, P.; Di Stefano, C.; Valenti, A. The Wood in Acqualadrone (ME-Sicily) Roman Rostrum. 4th International Congress "Science and Technology for the Safeguard of Cultural Heritage of the Mediterranean Basin”. http:// www.cairocongress.com/index.asp (accessed March 28, 2012).

(3) Caruso, F.; Saladino, M. L.; Spinella, A.; Di Stefano, C.; Tisseyre, P.; Tusa, S.; Caponetti, E. Archaeometry 2011, 53, 547-562.

(4) Murray, W. The Age of Titans-The Rise and Fall of the Great Hellenistic Navies; Oxford University Press Inc.: New York, 2012; p 50.

(5) Lazenby, J. F. The First Punic War: A Military History; Stanford University: Stanford, CA, 1996.

(6) Sandström, M.; Jalilehvand, F.; Persson, I.; Gelius, U.; Frank, P.; Hall-Roth, I. Nature 2002, 415, 893-897.

(7) Fors, Y.; Sandström, M. Chem. Soc. Rev. 2006, 35, 399-415.

(8) Fors, Y.; Nilsson, T.; Risberg, E. D.; Sandström, M.; Torssander, P. Int. Biodeterior. Biodegrad. 2008, 62, 336-347.

(9) MacLeod, I. D.; Kenna, C. ICOM-Committee for Conservation Working Group on Wet Organic Archaeological Materials, Bremerhaven, Germany, Aug 20-24, 1991; International Council of Museums (ICOM): Paris, 1991; pp 133-142.

(10) Sandström, M.; Jalilehvand, F.; Persson, I.; Fors, Y.; Damian, E.; Gelius, U.; Hall-Roth, I.; Dal, L.; Vicki, R.; Ian, G. Conservation Science 2002: Papers from the Conference Held in Edinburgh, Scotland 22-24 May 2002, s. 79-87 ed.; Archetype Publications: London, 2003.

(11) Sandström, M.; Jalilehvand, F.; Damian, E.; Fors, Y.; Gelius, U.; Jones, M.; Salomé, M. Proc. Natl. Acad. Sci. U.S.A. 2005, 100, 1416514170.

(12) Krause, M. O.; Oliver, H. H. J. Phys. Chem. Ref. Data 1979, 8, 329-338.

(13) Sarangi, R.; Frank, P.; Hodgson, K. O.; Hedman, B. Inorg. Chim. Acta 2008, 361, 956-964.

(14) Anxolabéhère-Mallart, E.; Glaser, T.; Frank, P.; Aliverti, G.; Zanetti, J.; Hedman, B.; Hodgson, K. O.; Solomon, E. I. J. Am. Chem. Soc. 2001, 123, 5444-5452.

(15) Frank, P.; Hedman, B.; Hodgson, K. O. Inorg. Chem. 1999, 38, 260-270.

(16) Frank, P.; DeBeer George, S.; Anxolabéhère-Mallart, E.; Hedman, B.; Hodgson, K. O. Inorg. Chem. 2006, 45, 9864-9876.

(17) Hedman, B.; Frank, P.; Penner-Hahn, J. E.; Roe, A. L.; Hodgson, K. O.; Carlson, R. M. K.; Brown, G.; Cerino, J.; Hettel, R.; Troxel, T.; Winick, H.; Yang, J. Nucl. Instrum. Methods Phys. Res. 1986, A246, 797-800. 
(18) George, G. N.; Gorbaty, M. L.; Kelemen, S. R.; Sansone, M. Energy Fuels 1991, 5, 93-97.

(19) Jalilehvand, F. Chem. Soc. Rev. 2006, 35, 1256-1268.

(20) Bugani, S.; Modugno, F.; Lucejko, J. J.; Giachi, G.; Cagno, S.; Cloetens, P.; Janssens, K.; Morselli, L. Anal. Bioanal. Chem. 2009, 395, 1977-1985.

(21) George, G. N.; Gorbaty, M. L. J. Am. Chem. Soc. 1989, 111, $3182-3186$.

(22) Dezarnaud, C.; Tronc, M.; Modelli, A. Chem. Phys. 1991, 156, $129-140$.

(23) Dezarnaud-Dandine, C.; Bournel, F.; Mangeney, C.; Tronc, M.; Modelli, A.; Jones, D. Chem. Phys. 2001, 265, 105-112.

(24) Anderson, A. B.; Riffer, R.; Wong, A. Phytochemistry 1969, 8, $873-875$.

(25) Colombini, M. P.; Giachi, G.; Modugno, F.; Pallecchi, P.; Ribechini, E. Archaeometry 2003, 45, 659-674.

(26) Simoneit, B. R. T.; Rogge, W. F.; Mazurek, M. A.; Standley, L. J.; Hildemann, L. M.; Cass, G. R. Environ. Sci. Technol. 1993, 27, 25332541.

(27) Mills, J. S.; White, R. Stud. Conserv. 1977, 22, 12-31.

(28) Connan, J.; Nissenbaum, A. J. Archaeol. Sci. 2003, 30, 709-719.

(29) Pollard, A. M.; Heron, C. Archaeological Chemistry, 2nd ed.; The

Royal Society of Chemistry: Cambridge, U.K., 2008; pp 235-269.

(30) Ribechini, E.; Modugno, F.; Colombini, M. P.; Evershed, R. P. J. Chromatogr., A 2008, 1183, 158-169.

(31) Fors, Y.; Jalilehvand, F.; Sandström, M. Anal. Sci. 2011, 27, 785.

(32) Tannazi, F.; Bunker, G. Phys. Scr. 2005, 2005, 953-956.

(33) Taylor, J. C.; Matulis, C. E. J. Appl. Crystallogr. 1991, 24, 14-17.

(34) Balachandran, U.; Dusek, J. T.; Maiya, P. S.; Ma, B.; Mieville, R.

L.; Kleefisch, M. S.; Udovich, C. A. Catal. Today 1997, 36, 265-272.

(35) Pickering, I. J.; George, G. N.; Yu, E. Y.; Brune, D. C.; Tuschak, C.; Overmann, J.; Beatty, J. T.; Prince, R. C. Biochemistry 2001, 40, $8138-8145$.

(36) Almkvist, G.; Boye, K.; Persson, I. J. Synchrotron Radiat. 2010, $17,683-688$.

(37) Almkvist, G.; Persson, I. New J. Chem. 2011, 35.

(38) Boye, K.; Almkvist, G.; Nilsson, S. I.; Eriksen, J.; Persson, I. Eur. J. Soil Sci. 2011, 62, 874-881.

(39) Weng, T.-C.; Waldo, G. S.; Penner-Hahn, J. E. J. Synchrotron Radiat. 2005, 12, 506-510.

(40) Bevington, P. R.; Robinson, D. K. Data Reduction and Error Analysis for the Physical Sciences, 3rd ed.; McGraw-Hill: Boston, MA, 2003.

(41) Morcos, S. A. J. Cons. Int. Explor. Mer. 1973, 35, 94-95.

(42) Lide, D. R., Ed. Properties of Seawater. Handbook of Chemistry and Physics, Internet version, http://www.hbcpnetbase.com, 92nd ed.; CRC Press: Boca Raton, FL, 2012.

(43) Hansch, C.; Leo, A.; Taft, R. W. Chem. Rev. 1991, 91, 165-195.

(44) Heitz, S.; Durgeat, M.; Guyot, M.; Brassy, C.; Bachet, B. Tetrahedron Lett. 1980, 21, 1457-1458.

(45) Reisch, C. R.; Moran, M. A.; Whitman, W. B. J. Bacteriol. 2008, 190, 8018-8024.

(46) van der Maarel, M. J. E. C.; Jansen, M.; Haanstra, R.; Meijer, W. G.; Hansen, T. A. Appl. Environ. Microbiol. 1996, 62, 3978-3984.

(47) Tripp, H. J.; Kitner, J. B.; Schwalbach, M. S.; Dacey, J. W. H.; Wilhelm, L. J.; Giovannoni, S. J. Nat. Lett. 2008, 452, 741-744.

(48) Struis, R. P. W. J.; Ludwig, C.; Barrelet, T.; Krähenbühl, U.; Rennenberg, H. Sci. Total Environ. 2008, 403, 196-206.

(49) Negishi, M.; Pedersen, L. G.; Petrotchenko, E.; Shevtsov, S.; Gorokhov, A.; Kakuta, Y.; Pedersen, L. C. Arch. Biochem. Biophys. 2001, 390, 149-157.

(50) Smith, E. A.; Grant, F.; Ferguson, C. M. J.; Gallacher, S. Appl. Environ. Microbiol. 2001, 67, 2345-2353.

(51) Donovan, C. J.; Garduño, R. A.; Kalmokoff, M.; Ku, J. C.; Quilliam, M. A.; Gill, T. A. Appl. Environ. Microbiol. 2009, 75, 69196923.

(52) Kodama, M. Aqua-BioSci. Monogr. 2010, 3, 1-38.

(53) Hernández-Sebastià, C.; Varin, L.; Marsolais, F. In Sulfur Metabolism in Phototrophic Organisms; Hell, R., Dahl, C., Knaff, D. B.,
Leustek, T., Eds.; Springer: Dordrecht, The Netherlands, 2008; Vol. 27.

(54) Vairavamurthy, M. A.; Maletic, D.; Wang, S.; Manowitz, B.; Eglinton, T.; Lyons, T. Energy Fuels 1997, 11, 546-553.

(55) Casas, J. M.; Paipa, C.; Godoy, I.; Vargas, T. J. Geochem. Explor. 2007, 92, 111-119.

(56) Baron, D.; Palmer, C. D. Geochim. Cosmochim. Acta 1996, 60, $185-195$.

(57) Kawano, M.; Tomita, K. Am. Mineral. 2001, 86, 1156-1165.

(58) Rogge, W. F.; Hildemann, L. M.; Mazurek, M. A.; Cass, G. R. Environ. Sci. Technol. 1998, 32, 13-22.

(59) San Feliciano, A.; Caballero, E.; Del Rey, B.; Sancho, I. Phytochemistry 1991, 30, 3134-3136.

(60) Giachi, G.; Bettazzi, F.; Chimichi, S.; Staccioli, G. J. Cult. Heritage 2003, 4, 75-83.

(61) Letelier, M. E.; Sanchez-Jofre, S.; Peredo-Silva, L.; CortesTroncoso, J.; Aracena-Parks, P. Chem.-Biol. Interact. 2010, 188, 220227.

(62) Lowson, R. T. Chem. Rev. 1982, 82, 461-497.

(63) Sun, J.; Stanbury, D. M. Inorg. Chim. Acta 2002, 336, 39-45.

(64) Bagiyan, G. A.; Koroleva, I. K.; Soroka, N. V.; Ufimtsev, A. V. Russ. Chem. Bull. 2003, 52, 1135-1141.

(65) Horner, L.; Basedow, O. H. Justus Liebigs Ann. Chem. 1958, 612, $108-131$.

(66) Wallace, T. J.; Schriesheim, A. Tetrahedron 1965, 21, 22712280.

(67) Black, B. H.; Hardy, D. R.; Morris, R. E.; Mushrush, G. W. Fuel Sci. Technol. Int. 1990, 8, 935-945.

(68) Tevault, D. E.; Mowery, R. L.; Smardzewski, R. R. J. Chem. Phys. 1981, 74, 4480-4487.

(69) Schoenfisch, M. H.; Pemberton, J. E. J. Am. Chem. Soc. 1998, 120, 4502-4513.

(70) Paulson, G. D. Bound and Conjugated Pesticide Residues, 29th ed.; American Chemical Society: Washington, DC, 1976; pp 86-102.

(71) Nagasawa, K.; Yoshidome, H. J. Org. Chem. 1974, 39, 16811685. 